\title{
Preface
}

Oncology

\section{A New Horizon in Liver Disease}

\author{
Masatoshi Kudo \\ Department of Gastroenterology and Hepatology, Kindai University Faculty of Medicine, Osaka-Sayama, Japan
}

On May 26-27, 2016, the 6th International Kyoto Liver Cancer Symposium (IKLS) was held in Kyoto in conjunction with the 89th annual meeting of the Japan Society of Ultrasonics in Medicine (JSUM), the 8th Asian Conference on Ultrasound Contrast Imaging (ACUCI), the 12th congress of the Asian Federation of Societies for Ultrasound in Medicine and Biology (AFSUMB), and the 36th annual meeting of the Japan Association of Breast and Thyroid Sonology (JABTS). The theme of this symposium was 'A New Horizon in Liver Disease'.

The 1st IKLS was held on Awaji Island, Hyogo, in 2005 , in conjunction with a single-topic conference on hepatocellular carcinoma (HCC) organized by the Japan Society of Hepatology (JSH) (Congress President: Prof. M. Kudo). The 2nd IKLS was held in Kobe in 2009, in conjunction with the 45th annual congress of the JSH (Congress President: Prof. M. Kudo). The 3rd IKLS was held in Osaka in 2011, in conjunction with the 2nd Asian Pacific Primary Liver Cancer Expert (APPLE) Meeting (Congress President: Prof. M. Kudo). The 4th IKLS was held in 2014 in Kyoto, in conjunction with the 50th annual congress of the Liver Cancer Study Group of Japan (Congress President: Prof. M. Kudo). The 5th IKLS was held in 2015 in Kyoto, in conjunction with the 6th APPLE Meeting (Congress President: Prof. M. Kudo).

All of these symposia were successful. This issue of $\mathrm{On}$ cology includes selected articles from the 6th IKLS.

Hagiwara et al. [1] describe the outcome of combination therapy with sofosbuvir and ledipasvir for those with chronic viral type $\mathrm{C}$ liver disease. They conclude that a favorable sustained viral response was achieved by sofosbuvir/ledipasvir therapy, even in elderly patients, those with liver cirrhosis, and those who underwent curative treatment for liver cancer.

Yada et al. [2] describe the influence of liver inflammation on measurements of liver stiffness in patients with autoimmune hepatitis. They conclude that the simultaneous use of shear wave and strain imaging [3], i.e., combinational elastography, was useful for evaluating not only the degree of liver fibrosis, but also the degree of liver inflammation.

Kwok et al. [4] report a case of malignant transformation of hepatocellular adenoma (HCA) in a 20-year-old male; this disease is very rare in Japan. Although the factors underlying HCA development are unclear, the diagnosis of $\beta$-catenin-activated HCA was correct in this case, in which HCC with similar immunopathological features and structural atypia might have developed from $\beta$-catenin-activated HCA. To the best of their knowledge, this is the first case to be reported in Japan $[5,6]$, although many such cases have been reported in Western countries.

Kono et al. [7] state that low mechanical index contrast tissue harmonic imaging was superior to conventional contrast harmonic imaging $[8,9]$ for the delineation of hepatic nodular lesions, and might provide better sonographic images to guide radiofrequency ablation and early responses to this type of treatment.

\section{KARGER}

(c) 2016 S. Karger AG, Basel 
Tochio et al. [10] report 4 cases of hepatic angiomyolipoma showing an abundance of CD68-positive cells. This was initially suggested by imaging [11], i.e., positive uptake of a contrast agent within the tumor during the postvascular (Kupffer) phase of Sonazoid-enhanced ultrasonography, and was finally confirmed pathologically by immunohistochemical staining for CD68. This is the first report that CD68-positive cells are abundant in hepatic angiomyolipoma [12].

Nishida and Kudo [13] describe the immunological microenvironment of HCC and its clinical implications. They state that the immune response to HCC is determined by the balance between tumor antigenicity and the immunological microenvironment within cancer tissues. The former is also attributed to the accumulation of mutations and aberrations in cellular signaling pathways [14]. They conclude that an immunosuppressive microenvironment within an HCC tumor may result in resistance to immunotherapies such as immune checkpoint blockade [15]; therefore, modification of the tumor microenvironment may restore normal anticancer immune responses.
Kudo [16] describes both basic research and ongoing clinical trials of immune checkpoint inhibitors with respect to HCC. The author states that the results of a phase I/II nivolumab trial are promising, with patients tolerating the treatment well. Currently, two phase III trials are ongoing: one is a first-line trial of nivolumab and the other is a second-line trial of pembrolizumab. Furthermore, combination trials of PD-1/PD-L1 and CTLA-4 in advanced $\mathrm{HCC}$ patients are ongoing, as are combination trials of locoregional therapy with immune checkpoint inhibitors [17]. The author notes that immune checkpoint inhibitors will open new avenues for the treatment of HCC.

Finally, I firmly believe that the articles presented herein will provide new insight into recent advances in the field of liver disease; thus, this issue will be a most valuable resource for all the readers of Oncology.

\section{Disclosure Statement}

The author declares no conflict of interest regarding this study.

\section{References}

1 Hagiwara S, Nishida N, Watanabe T, Sakurai T, Ida H, Minami Y, Takita M, Minami T, Iwanishi M, Chishina H, Ueshima K, Komeda Y, Arizumi T, Kudo M: Outcome of combination therapy with sofosbuvir and ledipasvir for chronic type C liver disease. Oncology DOI: $10.1159 / 000451010$.

2 Yada N, Sakurai T, Minami T, Arizumi T, Takita M, Hagiwara S, Ida H, Ueshima K, Nishida N, Kudo M: Influence of liver inflammation on liver stiffness measurement in patients with autoimmune hepatitis evaluation by combinational elastography. Oncology DOI: $10.1159 / 000451011$.

3 Kudo M: Prediction of hepatocellular carcinoma incidence risk by ultrasound elastography. Liver Cancer 2014;3:1-5.

4 Kwok WY, Hagiwara S, Nishida N, Watanabe T, Sakurai T, Ida H, Minami Y, Takita M, Minami T, Iwanishi M, Chishina H, Kono M, Ueshima K, Komeda Y, Arizumi T, Enoki E, Nakai T, Kumabe T, Nakashima O, Kondo F, Kudo M: Malignant transformation of hepatocellular adenoma. Oncology DOI: $10.1159 / 000451012$.

5 Kudo M: Malignant transformation of hepatocellular adenoma: how frequently does it happen? Liver Cancer 2015;4:1-5.
6 Kudo M: Surveillance, diagnosis, treatment, and outcome of liver cancer in Japan. Liver Cancer 2015;4:39-50.

7 Kono M, Minami Y, Iwanishi M, Minami T, Chishina H, Arizumi T, Komeda Y, Sakurai T, Takita M, Yada N, Ida H, Hagiwara S, Ueshima K, Nishida N, Kudo M: Contrast-enhanced tissue harmonic imaging versus phase inversion harmonic sonographic imaging for the delineation of hepatocellular carcinomas. Oncology DOI: 10.1159/000451014.

8 Minami Y, Kudo M: Imaging modalities for assessment of treatment response to nonsurgical hepatocellular carcinoma therapy: contrast-enhanced US, CT, and MRI. Liver Cancer 2015;4:106-114.

9 Liu GJ, Wang W, Lu MD, Xie XY, Xu HX, Xu ZF, Chen LD, Wang Z, Liang JY, Huang Y, Li W, Liu JY: Contrast-enhanced ultrasound for the characterization of hepatocellular carcinoma and intrahepatic cholangiocarcinoma. Liver Cancer 2015;4:241-252.

10 Tochio H, Tamaki E, Imai Y, Iwasaki N, Minowa $\mathrm{K}$, Chung $\mathrm{H}$, Suginoshita $\mathrm{Y}$, Inokuma $\mathrm{T}$, Kudo M: CD68-positive cells in hepatic angiomyolipoma. Oncology DOI: 10.1159/ 000451013 .
11 Murakami T, Tsurusaki M: Hypervascular benign and malignant liver tumors that require differentiation from hepatocellular carcinoma: key points of imaging diagnosis. Liver Cancer 2014;3:85-96.

12 Kudo M: Clinical practice guidelines for hepatocellular carcinoma differ between Japan, United States, and Europe. Liver Cancer 2015, 4:85-95.

13 Nishida N, Kudo M: Immunological microenvironment of hepatocellular carcinoma and its clinical implication. Oncology DOI: 10.1159/000451015

14 Kudo M: Recent advances in bioinformatics reveal the molecular heterogeneity of hepatocellular carcinoma. Liver Cancer 2014;3:6870.

15 Kudo M: Immune checkpoint blockade in hepatocellular carcinoma. Liver Cancer 2015;4: 201-207.

16 Kudo M: Immune checkpoint inhibition in hepatocellular carcinoma: basics and ongoing clinical trials. Oncology DOI: 10.1159/ 000451016.

17 Kim HY, Park JW: Clinical trials of combined molecular targeted therapy and locoregional therapy in hepatocellular carcinoma: past, present, and future. Liver Cancer 2014;3:917. 